\title{
Health Promoting Lifestyle Behaviors in Menopausal Women: A Cross-Sectional Study
}

\author{
Fereshte Shabani Asrami ${ }^{1,2}$, Zeinab Hamzehgardeshi ${ }^{2,3} \&$ Zohreh Shahhosseini $^{2,3}$ \\ ${ }^{1}$ Student Research Committee, Mazandaran University of Medical Sciences, Sari, Iran \\ ${ }^{2}$ Department of reproductive health and Midwifery, Nasibeh Nursing and Midwifery faculty, Mazandaran \\ University of Medical Sciences, Sari, Iran \\ ${ }^{3}$ Traditional and Complementary Medicine Research Center, Mazandaran University of Medical Sciences, Sari, \\ Iran
}

Correspondance: Zohreh Shahhosseini, Mazandaran University of Medical Sciences, Sari, Iran; Vesal Street, Amir Mazandarani Boulevard, Sari, Po Box, 4816715793, Mazandaran Province, Iran. Tel: 98-111-3336-7345. Fax: 98-111-3336-7342. E-mail: zshahhosseini@yahoo.com

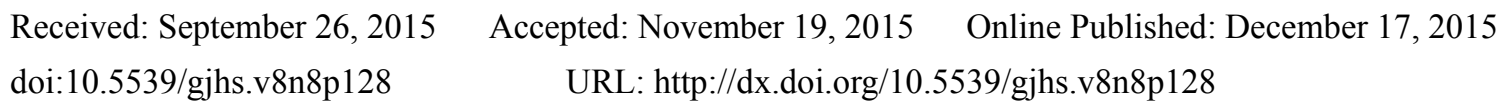

\begin{abstract}
Background: Determining health promoting lifestyle behaviors of age-specific groups of women provides valuable information for designing health promotion intervention programs. Hence the present study was conducted to assess health promoting lifestyle behaviors in menopausal women.
\end{abstract}

Methods: The present descriptive cross-sectional study examined health promoting lifestyle behaviors in 400 menopausal women admitted to health care centers in Neka city-north of Iran-from March 2015 to July 2015. Health promoting lifestyle behaviors were evaluated using a demographic characteristics form and the Health Promoting Lifestyle Profile II (HPLP II) through simple convenience sampling. Data were analyzed in SPSS version 18 using descriptive and inferential statistics at the significance level of $\mathrm{P}<0.05$.

Results: The mean score of participants' health promoting lifestyle behaviors was $136.43 \pm 19.61$, ranging from 88 to 194 . The logistic regression test revealed women's health promoting lifestyle behaviors to be significantly related to their place of residence $(\mathrm{P}=0.009$, odds ratio=1.73) and their spouse's level of education $(\mathrm{P}=0.027$, odds ratio $=0.58$ ). The Pearson correlation test showed significant relationships between mean score of the six sub-scale of health promoting lifestyle behaviors with each other $(\mathrm{P}<0.001)$.

Conclusion: These findings have implications for addressing the role of men to promote health promoting lifestyle behaviors among rural menopausal women.

Keywords: health promoting behaviors, menopausal women, health promotion

\section{Introduction}

Menopause is a developmental stage experienced by all women as they age. According to statistics, the world's population of menopausal women was 467 million in 1990. This population is expected to reach 1000.2 million women by 2030 (McKinlay, Brambilla, \& Posner, 1992; Nichols et al., 2006; Randhawa \& Sidhu, 2014). In Iran, there will be about five million menopausal women by 2021 and their life expectancy is currently about 70 years. Thus, it is expected they will to live nearly one third of their lives after menopause (Ayatollahi, Ghaem, \& Ayatollahi, 2005; Fallahian, 2004; Statistical Centre of Iran, 2011).

Menopausal changes that occur in women effect on different aspects of their health status like; reduce their physical activity, lead to sleep disorders, reduce their social activities and negatively related to their health promoting behaviors (Poomalar \& Arounassalame, 2013). Therefore, finding an appropriate and harmless health promoting solution to overcome these problems is essential (Gabriel, Mason, \& Sternfeld, 2015; Tehrani, Ghobadzadeh, \& Arastou, 2007).

Many of the serious complications that women face during menopause are caused by their own poor lifestyles and their lack of knowledge about self-care (Heidenreich, 2014; Kim, Lee, \& Johnson, 2015). To minimize these complications, efforts should be made to promote menopausal women's health. It is obvious that the promotion 
of health requires adherence to specific associated health behaviors (Baheiraei et al., 2011; Yeom, 2014).

Health promoting lifestyle behaviors are as active approaches to promote personal welfare and perceptions to maintain or enhance the level of wellness, self-actualization and fulfillment of the individual (Shaheen, Nassar, Amre, \& Hamdan-Mansour, 2015; Sousa, Gaspar, Vaz, Gonzaga, \& Dixe, 2015). They include behaviors through which the individual attempts to follow a proper diet, attempts to engages in regular exercise, attempts to avoids high-risk behaviors and drug use, attempts to protects herself against accidents, and pays attention to diverse physical dimensions, controlling emotions, feelings, and thoughts, defending against mental tensions and problems (Pullen, Walker, \& Fiandt, 2001).

Some studies conducted by means of Health Promoting Lifestyle Profile II (HPLP II) around the world show that health promoting lifestyle behaviors vary in different societies based on their particular socio-cultural-economic contexts. One study reported that the highest score of health promoting lifestyle behaviors in rural women was detected in nutritional status and the lowest in physical activity (Pullen et al., 2001). Meanwhile, another study conducted on Hispanic women found the highest score have been obtained in spiritual growth and the lowest in physical activity (Hulme et al., 2003). Also, in Korean farmers the highest score of health promoting lifestyle behaviors was shown to have related to nutrition, followed by spiritual growth, and the lowest to have been obtained in physical activity (Park, Kwon, \& Oh, 2009). Finally, another study on nurses showed the highest score of health promoting lifestyle behaviors was detected in nutrition dimension and interpersonal relationships and the lowest were related to physical activity and stress management (Edrisi et al., 2013).

Given the importance of health promoting lifestyle behaviors in menopausal women, the present study was conducted to assess these behaviors in menopausal women admitted to health care centers with the aim of addressing health-oriented programs for menopausal women.

\section{Method}

The present descriptive cross-sectional study examined health promoting lifestyle behaviors in 400 menopausal women admitted to health care centers in Neka city-north of Iran-from March 2015 to July 2015. The women with at least one year miss period of menstruation were selected through simple convenience sampling. Data were collected using a demographic characteristics form and the Health Promoting Lifestyle Profile II (HPLP II) measuring 52 health promoting lifestyle behaviors in a four point Likert scale type for each item ranging from 1(never) to 4(routinely). The HPLP II includes six sub-scales: health responsibility ( 9 items), physical activity (8 items), nutrition (9 items), spiritual growth (9 items), interpersonal relationships ( 9 items), and stress management ( 8 items).The overall score of the instrument range from 52 to 208, where each domain has its own separate score and higher scores indicate a better adherence to health promoting behavior. In this way, scores 52-103 means a low level of adherence to these behaviors and scores 104- 155 and score above 156 imply a moderate and high level, respectively.

This instrument was designed by Walker, Sechrist and Pender in 1987 to measure health promoting behaviors (Walker, Sechrist, \& Pender, 1987). It has been translated into many languages and has an acceptable validity and reliability (Pérez-Fortis, Díez, Sara, \& Padilla, 2012; Pinar, Celik, \& Bahcecik, 2009; Sousa, Gaspar, Fonseca, Hendricks, \& Murdaugh, 2015; Wang et al., 2007). A number of Iranian studies have evaluated psychometric properties of the Persian version of this profile too (Baheiraei et al., 2011; Mohamadian, Ghannaee, Kortdzanganeh, \& Meihan, 2013).

After submitting signed informed consent form, the participants were invited to complete the HPLP II. The ethical consideration of the research was observed from the Ethics Committee of Mazandaran University of Medical Sciences (No.93-179), obtaining letters of introduction from the relevant organizations and maintaining the confidentiality of the data.

Data were analyzed in SPSS version 18 using descriptive and inferential statistics including the independent $\mathrm{t}$-test, the analysis of variance, Pearson correlation test, and the logistic regression analysis at a significance level of $\mathrm{P}<0.05$.

\section{Results}

Participants' mean age and their mean age at menopause were reported as $57.53 \pm 7.63$ and $47.78 \pm 5.12$, respectively. A total of $44 \%$ of participants lived in cities, and the rest lived in rural areas. Table 1 presents the demographic characteristics of participants.

According to the results, mean score of health promoting lifestyle behaviors was $136.43 \pm 19.61$, ranging from 88 to 194 . The highest mean score in the subscales was $25.88 \pm 4.86$ for nutrition sub-scale followed by interpersonal relationship (25.82 \pm 5.02$)$ and spiritual growth $(25.45 \pm 4.46)$, and the lowest was $16.12 \pm 4.30$ for physical activity. 
Table 2 presents the mean score of health promoting lifestyle behaviors by place of residence.

The results also showed that health promoting lifestyle behaviors are significantly related to women's level of education $(\mathrm{F}=4.81, \mathrm{P}=0.003)$, their spouse's level of education $(\mathrm{F}=5.62, \mathrm{P}<0.001)$, and their location of residency $(\mathrm{t}=2.43, \mathrm{P}=0.011)$. However, the score of health promoting lifestyle behaviors was not found to be significantly related to the women's age $(\mathrm{r}=0.22, \mathrm{P}=0.655)$, age at menopause $(\mathrm{r}=0.28, \mathrm{P}=0.575)$, marital status $(\mathrm{t}=1.67$, $\mathrm{P}=0.097)$, employment status $(\mathrm{t}=0.57, \mathrm{P}=0.568)$, family structure $(\mathrm{F}=1.71, \mathrm{P}=0.163)$, and economic status $(\mathrm{t}=0.57, \mathrm{P}=0.567)$. The Pearson correlation test showed significant relationships between mean score of the six sub-scale of health promoting lifestyle behaviors with each other $(\mathrm{P}<0.001)$.

To provide a better interpretation of the relationships discovered, the Binary logistic regression analysis (cut off point $\geq 130$ score was considered as positive history of health promoting lifestyle behaviors) was conducted. The results showed that the score of health promoting lifestyle behaviors in menopausal women related to their location of residency $(\mathrm{P}=0.009$, odds ratio $=1.73)$ and their spouse's level of education $(\mathrm{P}=0.027$, odds ratio $=0.58)$. It means the mean score of health promoting lifestyle behaviors was significantly higher in urban women compared to rural ones and women who also had better educated spouses had a better adherence to health promoting lifestyle behaviors (Table 3).

Table 1. Socio-demographic characteristics of the participants

\begin{tabular}{lll}
\hline Age(yr)* & $57.53 \pm 7.63$ & \\
\hline Menopausal age(yr) $^{*}$ & $47.78 \pm 5.10$ & $176(44)$ \\
\hline Residency of location** & Urban & $224(56)$ \\
& Rural & $339(84.8)$ \\
Marital status** & Married & $61(15.2)$ \\
& Widow/Divorced & $354(88.5)$ \\
Level of education** & Primary & $39(9.8)$ \\
& Secondary & $7(1.7)$ \\
Employment Status $^{* *}$ & Academic & $385(96.3)$ \\
& Household & $15(3.7)$ \\
Family structure & Employed & $326(81.5)$ \\
& Living with husband & $48(12.1)$ \\
Education of husband & Living with children & $26(6.4)$ \\
& Living alone & $286(71.5)$ \\
Economic status & Primary & $96(24)$ \\
& Secondary & $18(4.5)$ \\
\hline
\end{tabular}

${ }^{*}$ Mean $\pm \mathrm{SD} ;{ }^{* *}$ Frequency (Percent).

Table 2- Mean and standard deviation of health promoting behaviors score by location of residency

\begin{tabular}{|c|c|c|c|c|}
\hline & Urban $\mathrm{N}=176$ & Rural N=224 & & Total $\mathrm{N}=400$ \\
\hline & Mean \pm SD & Mean \pm SD & $l$ & Mean \pm SD \\
\hline Health Responsibility & $23.63 \pm 4.86^{* *}$ & $23.53 \pm 4.10^{* *}$ & 0.88 & $23.57 \pm 4.45^{* *}$ \\
\hline Physical Activity & $15.76 \pm 4.37^{* * *}$ & $16.41 \pm 4.24^{* * * *}$ & -1.50 & $16.12 \pm 4.30^{* * *}$ \\
\hline Nutrition & $27.64 \pm 5.28^{* *}$ & $24.50 \pm 3.99^{* *}$ & $6.55^{*}$ & $25.88 \pm 4.86^{* *}$ \\
\hline Spiritual Growth & $25.69 \pm 4.79^{* *}$ & $25.27 \pm 4.17^{* *}$ & 0.91 & $25.45 \pm 4.46^{* *}$ \\
\hline Interpersonal Relationship & $26.69 \pm 5.67^{* *}$ & $25.13 \pm 4.34^{* *}$ & $3.00^{*}$ & $25.82 \pm 5.02^{* *}$ \\
\hline Stress Management & $19.78 \pm 4.30^{* * * *}$ & $19.43 \pm 3.29^{* * * *}$ & 0.88 & $19.59 \pm 3.77^{* * * *}$ \\
\hline Total Score & $139.17 \pm 21.75$ & $134.27 \pm 17.5$ & $2.43^{*}$ & $136.43 \pm 19.61$ \\
\hline
\end{tabular}

${ }^{*} P<0.05$ was considered statistically significant; ${ }^{* *}$ Total score ranged $9-36 ;{ }^{* * *}$ Total score ranged $8-32$. 
Table3. Logistic regression analysis for variables predicting health promoting behaviors in menopausal women

\begin{tabular}{lllllll}
\hline & \multirow{2}{*}{$\mathrm{B}$} & \multirow{2}{*}{ Std.Error } & \multirow{2}{*}{ Sig. } & \multirow{2}{*}{ EXP(B) } & \multicolumn{2}{c}{ 95\% Confidence Interval for B } \\
\cline { 6 - 7 } & & & & & Lower & Upper \\
\hline Location of residency & 0.552 & 0.210 & 0.009 & 1.736 & 1.151 & 2.619 \\
Level of education & -0.639 & 0.365 & 0.080 & 0.528 & 0.258 & 1.078 \\
Husbands' level of education & -0.534 & 0.242 & 0.027 & 0.586 & 0.365 & 0.942 \\
Constant & 0.970 & 0.349 & 0.005 & 2.637 & & \\
\hline
\end{tabular}

\section{Discussion}

The mean score of health promoting lifestyle behaviors of our participants was reported in moderate range, which is consistent with other studies conducted in Iranian perimenopausal middle-aged women (Enjezab, Farajzadegan, Taleghani, Aflatoonian, \& Morowatisharifabad, 2012; Sehhatie, Mirghafourvand, \& Momeni, 2015 ) and younger Iranian nurses (Edrisi et al., 2013). It seems women necessitate a greater attention of policy makers and health care services to promote health promoting training programs targeting them. Although In a study among Taiwanese women the mean of the overall score for health promoting lifestyle behaviors fell within the low range (Lee \& Wang, 2005), possibly indicating cultural differences in health behaviors between Iranian and Taiwanese women, thus justifying the need for conducting further studies in different countries.

In attention to numerous studies have shown physical activity has positive effects on menopausal symptoms (Daley et al., 2015; Kim, Cho, Ahn, Yim, \& Park, 2014; Sternfeld et al., 2014) and low physical activity score in this research along with other studies (Hulme et al., 2003; Kirag \& Ocaktan, 2013; Park et al., 2009; Pullen et al., 2001), the need for interventional programs for menopausal women is recommended.

In the present study, in line with some studies, the results showed significantly higher scores of health promoting lifestyle behaviors in urban women compared to rural ones (Park, 2002), although in some studies there is no evidences to support this (Lee, 2009; Query, 2014). This differences in results may be due to the fact that rural women, in north of Iran, traditionally, are more involved in agricultural work (Sehhatie et al., 2015) and may less pay to attention to health promoting behaviors, so more research is necessary before a conclusion can be made.

Our finding regarding to the relationship between women's health promoting lifestyle behaviors and their spouse's level of education may be considered as a noticeable issue in this project. As, especially, in developing countries, men could be decision-makers in issues related to women's health (Khani, Banaem, Mohammadi, Vedadhir, \& Hajizadeh, 2014; Mboane \& Bhatta, 2015; Speizer, Whittle, \& Carter, 2005), their role must be kept in mind in policies related to health promotion of their wives and the less educated men appear to require more careful training and planning in this regard.

Despite some studies have shown more educated women have higher score in health promoting lifestyle behaviors (Arras, Ogletree, \& Welshimer, 2006; Bond, Jones, Cason, Campbell, \& Hall, 2002; Meihan \& Chung-Ngok, 2011; Sohng, Sohng, \& Yeom, 2002), in our study there is no evidences to support this (El Mokadem, 2013). This may be because the majority (88.5\%) of participants in this study, in accordance with normal population of menopausal women in Iranian society, (Statistical Centre of Iran, 2011) had primary education. Also it is not clear that someone with higher school education have an understanding of the importance of certain health promoting behaviors? More population-based studies with considering determinants of health promoting behaviors may be helpful in the future.

In conclusion, it seems the level of education of women's husbands can predict menopausal women adherence to health promoting behaviors. Hence, the less educated men appear to require more careful training and planning in this regard. Moreover, the poorer adherence to health promoting lifestyle behaviors in rural women necessitate a greater attention of health policy makers to holding health training programs targeting this group of menopausal women.

One limitation of the present study is that it was conducted on women admitted to health care centers, and its results are, therefore, only applicable to this group of women. Future studies are recommended to be conducted through population-based design research in order to visit menopausal women in their place of residence.

\section{Acknowledgments and Funding}

This research was supported by a grant from Mazandaran University of Medical Sciences (Grant No. 93-179). We would like to express our appreciation to menopausal women for their cooperation in this study. 
This project was funded and supported by Student Research Committee, Mazandaran University of Medical Sciences, Grant No. 93-179.

\section{Conflict of Interest}

The authors declare that there is no conflict of interests regarding the publication of this paper.

\section{References}

Arras, R. E., Ogletree, R. J., \& Welshimer, K. J. (2006). Health-promoting behaviors in men age 45 and above. International Journal of Men's Health, 5(1), 65-79. http://dx.doi.org/10.3149/jmh.0501.65

Baheiraei, A., Mirghafourvand, M., Mohammadi, E., Nedjat, S., Charandabi, S. M., Rajabi, F., \& Majdzadeh, R. (2011). Health-promoting behaviors and social support of women of reproductive age, and strategies for advancing their health: Protocol for a mixed methods study. BMC public health, 11(1), 191. http://dx.doi. org/10.1186/1471-2458-11-191

Bond, M. L., Jones, M. E., Cason, C., Campbell, P., \& Hall, J. (2002). Acculturation effects on health promoting lifestyle behaviors among Hispanic origin pregnant women. Journal of Multicultural Nursing \& Health, $8(2), 61-68$.

Daley, A., Thomas, A., Roalfe, A., Stokes-Lampard, H., Coleman, S., Rees, M., ... MacArthur, C. (2015). The effectiveness of exercise as treatment for vasomotor menopausal symptoms: Randomised controlled trial. BJOG: An International Journal of Obstetrics \& Gynaecology, 122(4), 565-575. http://dx.doi.org/10.1111/ 1471-0528.13193

Edrisi, M., Khademloo, M., Ghorban, A. A., Gooran, F., Khalili-Azandehi, H., Bahrami, B., \& Hesamzadeh, A. (2013). Self Report of Health Promoting Behaviors of Nurses Working in Teaching Hospitals. $J$ Mazandaran Univ Med Sci, 23(105), 52-59.

El Mokadem, N. M. (2013). Health Promoting Lifestyle Behaviors among Women at High Risk for Cardiovascular Diseases. The Medical Journal of Cairo University, 81(1), 83-88.

Enjezab, B., Farajzadegan, Z., Taleghani, F., Aflatoonian, A., \& Morowatisharifabad, M. A. (2012). Health promoting behaviors in a population-based sample of middle-aged women and its relevant factors in Yazd, Iran. International Journal of Preventive Medicine, 3(1), 191-198.

Gabriel, K. P., Mason, J. M., \& Sternfeld, B. (2015). Recent evidence exploring the associations between physical activity and menopausal symptoms in midlife women: Perceived risks and possible health benefits. Women's Midlife Health, 1(1), 1-28. http://dx.doi.org/10.1186/s40695-015-0004-9

Heidenreich, P. A. (2014). Healthy Lifestyles and Personal Responsibility. Journal of the American College of Cardiology, 64(17), 1786-1788. http://dx.doi.org/10.1016/j.jacc.2014.08.016

Hong, E., Kang, Y. S., \& Ha, Y. (2013). Factors affecting on health promoting behaviors among teachers with middle-aged women experiencing menopause. Korean Journal of Occupational Health Nursing, 22(1), 66-74. http://dx.doi.org/10.5807/kjohn.2013.22.1.66

Hulme, P. A., Walker, S. N., Effle, K. J., Jorgensen, L., McGowan, M. G., Nelson, J. D., \& Pratt, E. N. (2003). Health-promoting lifestyle behaviors of Spanish-speaking Hispanic adults. Journal of Transcultural Nursing, 14(3), 244-254. http://dx.doi.org/10.1177/1043659603014003011

Khani, S., Banaem, L. M., Mohammadi, E., Vedadhir, A., \& Hajizadeh, E. (2014). The most Common Sexual and Reproductive Health Needs in Women Referred to Healthcare and Triangle centers of Sari-2013. Journal of Mazandaran University of Medical Sciences, 23(1), 43-51.

Kim, M. H., Lee, J. S., \& Johnson, M. A. (2015). Poor Socioeconomic and Nutritional Status Are Associated with Osteoporosis in Korean Postmenopausal Women: Data from the Fourth Korea National Health and Nutrition Examination Survey (KNHANES) 2009. Journal of the American College of Nutrition, 34(5), 400-407. http://dx.doi.org/10.1080/07315724.2014.945197

Kim, M. J., Cho, J., Ahn, Y., Yim, G., \& Park, H. Y. (2014). Association between physical activity and menopausal symptoms in perimenopausal women. BMC women's health, 14(1), 122. http://dx.doi.org/10. $1186 / 1472-6874-14-122$

Kirag, N., \& Ocaktan, E. M. (2013). Analysis of health promoting lifestyle behaviors and associated factors among nurses at a university hospital in Turkey. Saudi Medical Journal, 34(10), 1062-1067.

Lee, C. J. (2009). A comparison of health promotion behaviors in rural and urban community-dwelling spousal 
caregivers. Journal of Gerontological Nursing, 35(5), 34-40. http://dx.doi.org/10.3928/00989134-20 090331-04

Lee, F. H., \& Wang, H. H. (2005). A preliminary study of a health-promoting lifestyle among Southeast Asian women in Taiwan. The Kaohsiung Journal of Medical Sciences, 21(3), 114-120. http://dx.doi.org/10.1016/ S1607-551X(09)70287-6

Mboane, R., \& Bhatta, M. P. (2015). Influence of a husband's healthcare decision making role on a woman's intention to use contraceptives among Mozambican women. Reproductive health, 12(1), 36. http://dx.doi. org/10.1186/s12978-015-0010-2

McKinlay, S. M., Brambilla, D. J., \& Posner, J. G. (1992). The normal menopause transition. American Journal of Human Biology, 4(1), 37-46. http://dx.doi.org/10.1002/ajhb.1310040107

Meihan, L., \& Chung-Ngok, W. (2011). Validation of the psychometric properties of the health-promoting lifestyle profile in a sample of Taiwanese women. Quality of Life Research, 20(4), 523-528. http://dx.doi. org/10.1007/s11136-010-9790-6

Mohamadian, H., Ghannaee, M., Kortdzanganeh, J., \& Meihan, L. (2013). Reliability and construct validity of the Iranian version of health-promoting lifestyle profile in a female adolescent population. International Journal of Preventive Medicine, 4(1), 42.

Nichols, H. B., Trentham-Dietz, A., Hampton, J. M., Titus-Ernstoff, L., Egan, K. M., Willett, W. C., \& Newcomb, P. A. (2006). From menarche to menopause: Trends among US women born from 1912 to 1969. American Journal of Epidemiology, 164(10), 1003-1011. http://dx.doi.org/10.1093/aje/kwj282

Park, J. S. (2002). The comparative study on the health promotion life style and perceived health status of elderly in urban and rural area. Journal of Agricultural Medicine and Community Health, 27(2), 137-148.

Park, J. S., Kwon, S. M., \& Oh, Y. J. (2009). Health promotion behavior, health problems, perceived health status and farmers' syndrome of rural residents. Journal Of Agricultural Medicine And Community Health, 34(1), 47-57. http://dx.doi.org/10.5393/JAMCH.2009.34.1.047

Pérez-Fortis, A., Díez, U., Sara, M., \& Padilla, J. L. (2012). Psychometric properties of the Spanish version of the health-promoting lifestyle profile II. Research in Nursing \& Health, 35(3), 301-313. http://dx.doi.org/ 10.1002/nur.21470

Pinar, R., Celik, R., \& Bahcecik, N. (2009). Reliability and construct validity of the Health-Promoting Lifestyle Profile II in an adult Turkish population. Nursing research, 58(3), 184-193. http://dx.doi.org/10.1097/NNR. 0b013e31819a8248

Poomalar, G., \& Arounassalame, B. (2013). The quality of life during and after menopause among rural women. Journal of clinical and diagnostic research: JCDR, 7(1), 135.

Pullen, C., Walker, S. N., \& Fiandt, K. (2001). Determinants of Health-Promoting Lifestyle Behaviors in Rural Older Women. Family \& Community Health, 24(2), 49-72. http://dx.doi.org/10.1097/00003727-20010 7000-00008

Query, B. A. (2014). Health Status, Health Promoting Behaviors, and Facilitators and Barriers to Health Promoting Behaviors of Urban versus Rural Primary Caregivers of Children with Disabilities. University of Alberta.

Randhawa, R., \& Sidhu, S. (2014). Age at natural menopause and menopausal symptoms among rural women of Amritsar (Punjab). Medical Science, 7(24), 48-55.

Sehhatie, F., Mirghafourvand, M., \& Momeni, K. (2015). Health Promoting Behaviors among Postmenopausal Women in Langroud City, Iran. Health, 3(3), 158-162. http://dx.doi.org/10.15296/ijwhr.2015.33

Shaheen, A. M., Nassar, O. S., Amre, H. M., \& Hamdan-Mansour, A. M. (2015). Factors Affecting Health-Promoting Behaviors of University Students in Jordan. Health, 7(01), 1. http://dx.doi.org/10.4236 /health.2015.71001

Sohng, K. Y., Sohng, S., \& Yeom, H. A. (2002). Health-Promoting Behaviors of Elderly Korean Immigrants in the United States. Public Health Nursing, 19(4), 294-300. http://dx.doi.org/10.1046/j.1525-1446.2002. 19409.x

Sousa, P., Gaspar, P., Fonseca, H., Hendricks, C., \& Murdaugh, C. (2015). Health promoting behaviors in adolescence: validation of the Portuguese version of the Adolescent Lifestyle Profile. Jornal de pediatria. 
http://dx.doi.org/10.1016/j.jped.2014.09.005

Sousa, P., Gaspar, P., Vaz, D. C., Gonzaga, S., \& Dixe, M. A. (2015). Measuring Health-Promoting Behaviors: Cross-Cultural Validation of the Health-Promoting Lifestyle Profile II. International journal of nursing knowledge, 26(2), 54-61. http://dx.doi.org/10.1111/2047-3095.12065

Speizer, I. S., Whittle, L., \& Carter, M. (2005). Gender relations and reproductive decision making in Honduras. International Family Planning Perspectives, 31(3), 131-139. http://dx.doi.org/10.1363/3113105

Statistical Centre of Iran. (2011). Iran Statistical Yearbook: Population by age and sex, 2011 Census. Retrieved January 2011, from http://www.sci.org.ir/portal

Sternfeld, B., Guthrie, K. A., Ensrud, K. E., LaCroix, A. Z., Larson, J. C., Dunn, A. L., ... Newton, K. M. (2014). Efficacy of exercise for menopausal symptoms: A randomized controlled trial. Menopause (New York, NY), 21(4), 330-338.

Tehrani, S. G., Ghobadzadeh, M., \& Arastou, M. (2007). Promoting Health Status of Menopausal Women by Educating Self Care Strategies. Hayat, 13(3), 67-75.

Walker, S. N., Sechrist, K. R., \& Pender, N. J. (1987). The Health-Promoting Lifestyle Profile: Development and psychometric characteristics. Nursing research, 36(2), 76-81. http://dx.doi.org/10.1097/00006199-19870 3000-00002

Wang, Y. J., Wu, L. J., Xia, W., Sun, C., Wei, C., \& Shang, T. (2007). Reliability and validity of Chinese version of the health-promoting lifestyle profile. Chinese Journal of School Health, 28(10), 89-91.

Yeom, H. E. (2014). Association among ageing-related stereotypic beliefs, self-efficacy and health-promoting behaviors in elderly Korean adults. Journal of clinical nursing, 23(9-10), 1365-1373. http://dx.doi.org/ 10.1111/jocn. 12419

\section{Copyrights}

Copyright for this article is retained by the author(s), with first publication rights granted to the journal.

This is an open-access article distributed under the terms and conditions of the Creative Commons Attribution license (http://creativecommons.org/licenses/by/3.0/). 